\title{
Developing Next Generation of Innovators: Teaching Entrepreneurial Mindset Elements across Disciplines
}

\author{
Louis S. Nadelson ${ }^{1}$, Aparna D. Nageswaran Palmer ${ }^{2}$, Tom Benton ${ }^{2}$, Ram Basnet ${ }^{2}$, Meghan Bissonnette ${ }^{2}$, Laureen \\ Cantwell ${ }^{2}$, Georgann Jouflas ${ }^{2}$, Eric Elliott ${ }^{2}$, Megan Fromm² \& Sarah Lanci ${ }^{2}$ \\ ${ }^{1}$ University of Central Arkansas, USA \\ ${ }^{2}$ Colorado Mesa University, USA \\ Correspondence: Louis S. Nadelson, Chair, Associate Professor, Leadership Studies College of Education, \\ University of Central Arkansas, USA
}

Received: August 1, 2018

doi:10.5430/ijhe.v7n5p114
Accepted: September 20, 2018

Online Published: September 27, 2018

\begin{abstract}
The purpose of our project was to explore the explicit or implicit engagement of faculty members across the curriculum in teaching the entrepreneurial mindset. We begin by defining entrepreneurship on a spectrum, recognizing the contextual nature and psychological development associated with entrepreneurial thinking. We developed a self-report survey containing a combination of quantitative and qualitative items to determine faculty member knowledge of entrepreneurship and their engagement in teaching elements of the entrepreneurial mindset. We surveyed the faculty at a primarily teaching university in the western United States. Sixty-four faculty members $(\sim 20 \%)$ with representation from across the disciplines completed our survey. We found constrained knowledge of entrepreneurship, indications of teaching elements of the entrepreneurial mindset, and approaches to assignments that were limited in scope for fostering entrepreneurial thinking. The implications of our research are a need for professional development to enhance faculty members' knowledge of entrepreneurial thinking and support for instructional and content choices that could enhance student development of an entrepreneurial mindset.
\end{abstract}

Keywords: entrepreneurship, entrepreneurial mindset, integrated curriculum, student centered learning

\section{Introduction}

There are many reasons for teaching entrepreneurship across the curriculum (Hindle, 2007). Developing a mindset that embraces, processes, and acts upon ideas of entrepreneurship requires instruction and support. The ability to handle novel situations, work with others, persevere in situations of failure and connect people and ideas to create new understanding is critical for being competitive and successful in the global economy. Developing the mindset requires effort and support. While the mindset might be acquired through experience, the literature supports the idea that it is more efficient for people to develop elements of the entrepreneurial mindset through instruction (e.g. Mansfield, Busse, \& Krepelka, 1978). We maintain that students will develop an entrepreneurial mindset most effectively if they are engaged in opportunities to think about and apply the mindset concepts under a wide range of conditions and toward a variety of outcomes. Thus, there is justification for teaching students to be entrepreneurs if there is a desire for them to be entrepreneurial (Rodov \& Truong, 2015). When taught entrepreneurial skills, the potential for success is greatly increased, even when faced with extremely challenging situations (Johnson, Wubbenhorst, \& Schroeder, 2013). However, even with the potential benefit to all students to develop an entrepreneurial mindset, there remains question as to how much faculty members across the undergraduate curriculum are implicitly or explicitly teaching content or processes that foster the development of an entrepreneurial mindset.

In our search of the literature, we were not able to identify any empirical reports of how the entrepreneurial mindset is being taught explicitly or implicitly across the curriculum at universities. To begin to fill this gap we conducted a survey-based research project in a teaching-focused university in the western United States in an attempt to gather data from faculty members across the curriculum. Before we report our approach and results we present a plausible definition of entrepreneurship and a review of the literature associated with teaching entrepreneurship at the university level. 


\section{Review of Literature}

\subsection{Defining Entrepreneurship}

For several decades there has continued to be a lack of a concrete, standard and universally accepted definition of the entrepreneur and entrepreneurship (e.g. Brockhaus \& Howitz, 1986, Chell et al., 1991, Kirby, 2004). Entrepreneurship may have different meanings and therefore different definitions in various disciplines. Because of the multi-disciplinary nature of the works an entrepreneur may be practicing the content, theories, and insights to define entrepreneurship, and they may have been borrowed from various fields such as marketing, accounting, finance, management, sociology, psychology, engineering, etc. According to M. M. Morris (personal communication, Sept. $21-24,2017$ ), entrepreneurs create value by synthesizing original ideas through the novel assembly of resources and process to take advantage of opportunity. Similarly, Kuratko and Hodgetts (2004) contend that the combination of vision, change and development lead to new ideas and solutions. Kuratko and Hodgetts also posit that entrepreneurs take risks acting on "opportunity where others see chaos, contradiction, and confusion" (p 30).

Commonly the term entrepreneur is overly simplified and often used as a synonym for small business owners (Gibb, 1996). We maintain that being entrepreneurial is not limited to association with business ownership. Rather, we perceive entrepreneurship as a way of thinking for approaching problems, implementing innovations, finding solutions, sharing ideas, and making change happen. While entrepreneurial thinking could be applied to starting a new business, diversification within an existing business, and for considering and developing new product lines, we claim that entrepreneurship should be conceived more broadly as a frame of mind that individuals can apply in their approaches to life. People who embrace entrepreneurial thinking are change agents or disruptors, think beyond the status quo, and are motivated to make things happen. Thus, entrepreneurs may be professionals seeking to advance their fields (e.g., artists exploring new ways of producing their art, teachers developing novel approaches to engaging their students in learning, etc.). Because entrepreneurial thinking can be applied broadly, there is justification for considering the construct broadly and seeking to be inclusive and flexible to encompass a wide range of possible instances of entrepreneurship.

\subsection{An Entrepreneurship Spectrum}

We argue that entrepreneurship should be defined on a spectrum based on the extent to which the essential components of entrepreneurship are articulated or implemented. The essential components of entrepreneurship that we considered in our development of our entrepreneurial spectrum are:

- Engaging in visionary thinking and creativity (e.g. CITE);

- Taking advantage of opportunities;

- High levels of motivation, tenacity, and resilience;

- Taking action using innovative or novel approaches;

- Reliance on curiosity;

- Tolerance for ambiguity;

- Calculated risk-taking;

- High levels of self-regulation;

- Constant monitoring of needs and progress toward goals when taking action.

Individuals who are more conservative in their approaches to innovation and those who lack curiosity and do not engage in creative problem-solving are likely to be at the lower end of the entrepreneurial spectrum (see Figure 1). People with moderate levels of innovative thinking tend to be somewhat curious and engage in moderate level of creative problem solving and, therefore, we would place them near the middle of the spectrum. Individuals who frequently take innovative approaches to problem solving, seek novelty, are highly curious, and engage in a high level of creative problem solving would be defined as being at the higher end of the entrepreneurial spectrum. 


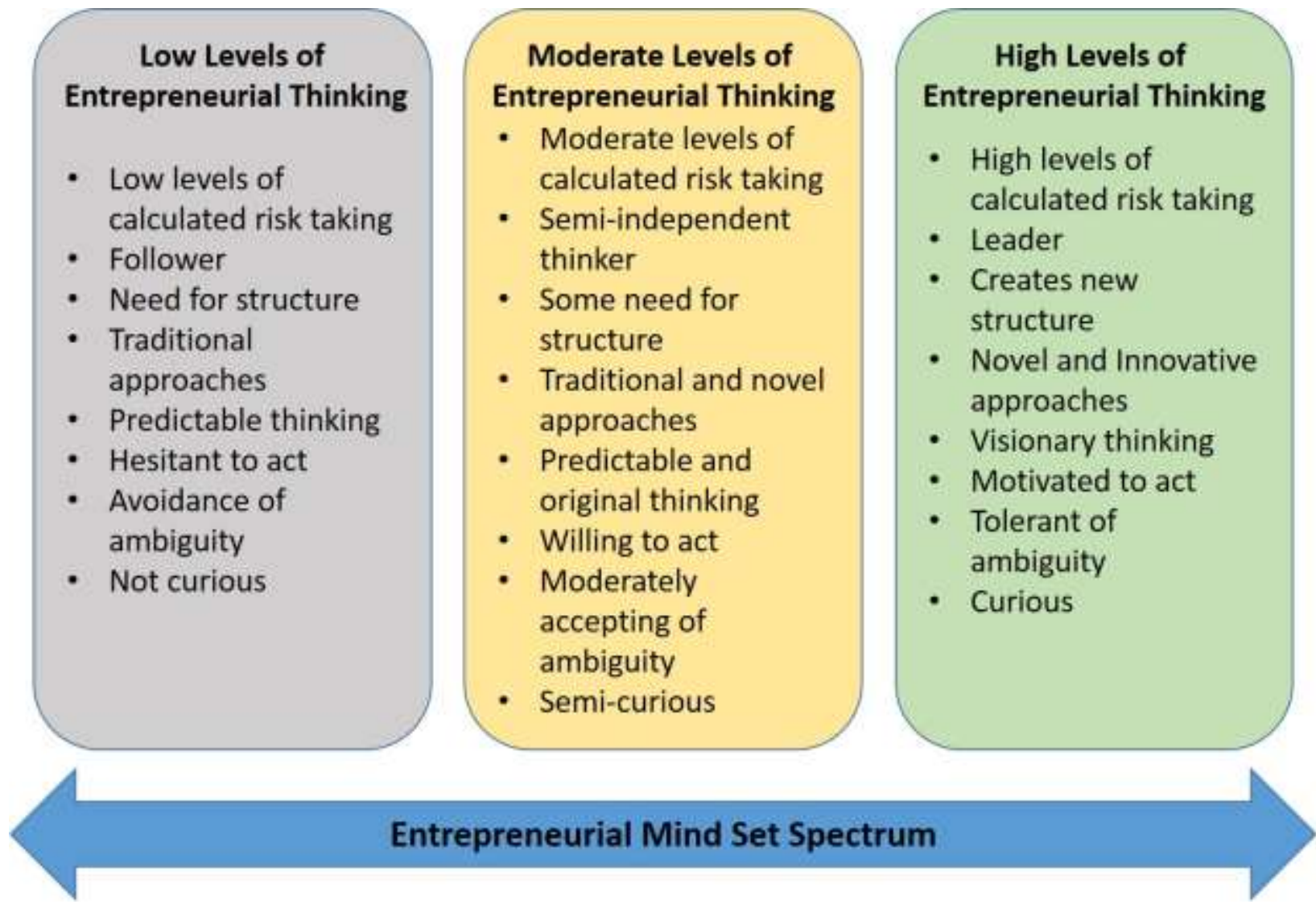

The entrepreneurial mindset spectrum.

We do recognize that the placement of individuals on the spectrum is likely to be contextual and, therefore, may be related to both the traits of the individual and the state or context in which the entrepreneurial activities are taking place. Further, the level of individual engagement or self-perceived embrace of entrepreneurial thinking may be substantially influenced by their culture, society, ethnicity, and worldview (Chrisman, Chua, \& Steier, 2002; Danes, Lee, Stafford, $\&$ Heck, 2008). While lack of knowledge may limit the ability of an individual to be entrepreneurial, the lack of commitment to an idea or framework may allow one to think outside the box and be more innovative and creative in approaching problems to design and develop solutions.

\subsection{Tolerance for Ambiguity}

Tolerance for ambiguity is defined as tendency to perceive ambiguity as a positive condition, not as a threat, but rather as an opportunity (Lumpkin \& Erdogan, 2004). Furnham and Ribchester (1995) focus on ambiguity tolerance in terms of a scale with one end being low or no tolerance and the other end being great or high tolerance. People at the low tolerance end of the scale avoid ambiguity and tend to react negatively to ambiguous situations with increased anxiety or rash decision-making. Individuals at the high tolerance end of the scale tend to embrace ambiguity as stimulating, novel, and as an opportunity.

Tolerance for ambiguity has been found to be related to other facets of the entrepreneurial mindset such as creativity (Tegano, 1990) and more productive brainstorming (Comadena, 1984). Thus, individuals with higher tolerance for ambiguity are more likely to be entrepreneurial and have developed other skills associated with the entrepreneurial mindset (Hvide \& Panos, 2014). Further, Teoh and Foo (1997) report that individuals with high levels of ambiguity tolerance actually perform better as entrepreneurs.

Tolerance for ambiguity can be taught through the use of projects that are open ended and ill-structured (Huber, 2003). Given the potential that some students may have a low level of tolerance for ambiguity and therefore feel anxiety and frustration when faced with ill-structured problems, faculty members may need to prepare their students for engaging in these learning situations (DeRoma, Martin, \& Kessler, 2003). We argue that given the potential influence of how and what faculty members teach their students on their development of tolerance of ambiguity there is justification for gathering the associated data. 


\subsection{Creativity and Innovation and Novel Approaches}

Innovation leads to creative and novel approaches that are essential components of the entrepreneurial mindset (Fontela, Guzman, Perez, \& Santos, 2006). Innovation involves non-linear thinking and versatility, which leads to the consideration of multiple possibilities and original solutions or approaches (Groves, Vance, \& Choi, 2011; Vance, Zell, \& Groves, 2008). Beauman (2006) argues that leadership is associated with innovative thinking and the actions of an entrepreneur, and without leadership, creative or innovative approaches are unlikely to progress from idea to attainment. The association among leadership, innovation, and the entrepreneurial mindset, suggest that there is benefit to faculty members using their positions of leadership to help students develop their propensity for creative and innovative thinking.

Many scholars have attempted to determine exactly how innovation and novel thinking are conceptualized in higher education instruction. Cai (2017) found the term "innovation" is often associated with ideas about radical reform or changes in classroom and assessment approaches. Recently, changes in pedagogical best practices have identified student-led inquiry, project-based learning, and flipped classrooms as models with the capacity to lead the student development of innovative thinking and encourage student consideration of novel approaches. For example, Foster and Yaoyuneyong (2016) found that implementing real-world-based projects with students from different business classes across an entire semester helped their students to develop an appreciation for the innovation process that also helped them feel more confident as they approached real-world working scenarios. In their graduate-level marketing classes, Lee and Benza (2015) found that encouraging innovative thinking required emphasis on skills such as discipline-specific expertise, open-mindedness and experimentation. They used a design-thinking classroom methodology to facilitate the students' learning experience. In particular, design thinking as an approach to teaching innovation and novel thinking with emphasis on solutions-based processes that are collaborative and iterative. Because of the possible influence of faculty members' instructional and content decisions on student development of a propensity for innovative and novel approaches to problem solving, there is a warrant to examining the extent to which faculty members across the curriculum are teaching in ways that foster development of students' abilities to consider innovative and novel approaches.

\subsection{Motivation, Resilience and Tenacity}

Motivation has been explored extensively leading to the development of multiple models to represent the construct (e.g., Schunk, Meece, Pintrich, 2014). Regardless of the model that is considered, the general premise of motivation involves taking action on a personal desire to achieve a goal. The influences on motivation development are extensive (e.g., Ryan \& Deci, 2017). However, it is widely accepted that we can teach people in ways that increase their motivation development (e.g., Furnham \& MacRae, 2017; Heckhausen, 2000).

Motivation is expressed through actions aligned with indicators of resilience, tenacity, and determination. We consider resilience as the ability to persevere when faced with failure, adversity, or resistance. Relatedly, tenacity and determination are defined as the persistence in efforts to achieve a goal. Unlike resilience, tenacity and determination are not usually associated with failure or adversity, but rather the complexity or difficulty of achieving the goal. Given the potential for challenges, complexity, failure, and adversity when engaging in entrepreneurial activities, there is justification for examining the relationship among motivation, resilience, tenacity, and determination when examining entrepreneurial thinking.

The extent of entrepreneurial success has been predicted by elements of resilience (Ayala \& Manzano, 2014; Fisher, Maritz, \& Lobo, 2016). Similarly, Ireland, Covin and Kuratko (2009) address the energy and passion, or tenacity and determination, needed to engage in the innovation and novel solutions associated with entrepreneurial activities. Kuratko also maintains that tenacity is needed to promote ideas and convince others that the idea is worth pursuing, even though it may not be tested or familiar. Since tenacity, motivation, determination, and persistence are necessary for engaging in entrepreneurial activities, there is justification for determining the extent to which university faculty members' content and instructional choices support student development of the mindset elements.

Resilience, tenacity, and determination can be taught (Dweck, Walton, \& Cohen, 2014; Hoerr, 2013; Seligman, 2011), suggesting that through the appropriate instructional and content choices, students can acquire the fundamental motivation skills associated with entrepreneurial success. Essig (2013) argues that educators can help students develop resilience by creating authentic conditions in which students can fail. Working with the students to persevere when faced with failure creates conditions in which the students may internalize the motivation necessary to develop a resilient mindset (Von Culin, Tsukayama, \& Duckworth, 2014). Thus, there is justification for determining if the instructional approaches and content choices of faculty members support student development of motivation through conditions that enhance the students' abilities to be resilient, tenacious, and determined. 


\subsection{Connecting People and Ideas}

Successful entrepreneurs are able to effectively make connections that lead to new ideas, opportunities, and increased productivity (e.g. Maritz, 2010). The impact of the network on innovation has been found to be influenced by brokerage between and among network nodes, size of the network, diversity of the network, and strength of the network (Baer, Evans, Oldham, \& Boasso, 2015). Given the benefit of multiple aspects of networking on entrepreneurial success, there is evidence to support the importance of teaching students ways to connect people and ideas to help them develop their entrepreneurial mindset.

Social media provides a context for teaching students how to connect people and ideas (Sacks \& Graves, 2012). While students may naturally use social media for their social interactions, they may need to be provided with specific contexts to effectively develop their use of social media to form networks that are supportive of entrepreneurship. In their review of entrepreneurship programs at multiple institutions, Standish-Kuon and Rice (2002) report that many of the programs provide opportunities for students to develop connections with program alumni that lead to activities that reinforce the power and benefit of connecting with people and ideas to being successful with entrepreneurial activities. Providing students with authentic contexts for networking and connecting people with ideas is fundamental to their development of skills and knowledge needed to be effective at networking in ways that are aligned with the entrepreneurial mindset (Taatila, 2010). Helping students learn to connect with people with a diversity of backgrounds and experiences, and listen to their ideas, is essential to students developing the skills to think beyond the expected and synthesize new solutions to complex problems (Nadelson \& Seifert, 2017).

Because students somewhat naturally engage in networking through their use of social media and tend to connect ideas based on societal and cultural influences, there is opportunity to leverage their social interactions to be more productive and lead to greater levels of entrepreneurial thinking. Therefore, there is justification for examining the extent to which faculty members implicitly or explicitly teach students to connect people and ideas as part of their course content and instruction.

\subsection{Curiosity}

A critical component to entrepreneurial thinking is curiosity (Wennekers \& Thurik, 1999). The general premise for the importance of curiosity for entrepreneurial thinking is that to explore new areas, try innovative approaches, develop new inventions, individuals need to be interested in the possibilities to the point they are willing to act on their curiosity (Jeraj, 2012). Thus, curiosity becomes the motivator to take action to pursue entrepreneurial goals (Jeraj, 2012). Because of the association between curiosity and entrepreneurial actions, there is support for helping students develop their curiosity.

Koranda and Sheehan (2014) indicate that if a course is structured appropriately there is a possibility that the proper content and instructional approaches can enhance student curiosity. Silvia $(2005,2008)$ reports that level of personal curiosity is predicated by perceptions of novelty and the students' perceived ability to attain task completion. Thus, providing students with assignments that are ill-structured and appropriately focused such that the assignments are challenging, yet attainable, (within their zone of proximal development) would likely foster their development of curiosity (Kashdan \& Fincham, 2004).

Given the association between curiosity and the entrepreneurial mindset and the ability to increase curiosity through instruction, there is justification to determine the extent that university faculty members across the disciplines are making content and instructional decisions that support student development of curiosity.

\subsection{Review Summary}

Through our review of the literature we determined that there is widespread support and approaches for helping students develop components of the entrepreneurial mindset. We also determined that there were a number of career and social benefits for students when they developed an entrepreneurial mindset. While the benefits, support, and approaches were found, we were not able to locate any studies that examined how faculty members across the curriculum taught in ways that implicitly or explicitly helped all students learn and develop and entrepreneurial mindset.

\section{Methods}

\subsection{Research Question}

Our overarching research question was: how are entrepreneurial mindset concepts taught implicitly or explicitly across the disciplines at the undergraduate level? To effectively answer our question, we developed a series of 
guiding research questions, which we used to frame the development of our research methods and contextualize our results. Our guiding research questions were:

- How do faculty members define entrepreneurship, and what is their self-perceived level of entrepreneurial thinking?

- To what level do faculty members engage in teaching facets of the entrepreneurial mindset?

- What kind of assignments do faculty use to foster student entrepreneurial mindset development?

\subsection{Participants}

The participants in our research were faculty members working at a primarily undergraduate university located in the western United States. We had 84 connects to our online survey; 64 of those completed at least $95 \%$ of the selected response items. Respondents included 34 males, 28 females, and 2 who did not answer. The sample was composed of 59\% of faculty members with doctorates and 34.5\% holding master's degrees as their highest degree; the remaining participants $(6.5 \%)$ held baccalaureate degrees. On average, the participants had worked for 13.9 years in higher education $(S D=13.5)$. Respondents were distributed across the disciplines with $27 \%$ from arts and humanities, 23\% from science, technology, engineering and mathematics (STEM), 34\% from professional program areas (e.g. education, business, criminal justice), $11 \%$ from social sciences, and 5\% indicating "other."

\subsection{Survey of Teaching Facets of the Entrepreneurial Mindset}

In our search of the extant literature we were not able to find any extant instruments designed to assess general faculty members' engagement in teaching facets of the entrepreneurial mindset. Therefore, we determined it was necessary to develop an instrument to gather the desired data from the faculty members. We began our development with multiple discussions about the critical facets of the entrepreneurial mindset that we should consider in relation to faculty members and their teaching. The critical facets we identified were: reliance, determination, persistence, innovative thinking, tolerance for the unknown, connecting people and ideas, and approaches used to teach entrepreneurship.

Once we identified the facets of the entrepreneurial mindset, we created four small groups from our team to develop a set of approximately 10 survey items in the context of one of the specific facets of interests. We compiled and then independently categorized the items in terms of the facet of entrepreneurial mindset. We continued to discuss the items until we either reached agreement or determined that the item was too ambiguous to be categorized and, therefore, we removed it from consideration.

After we categorized each of the items into our four facets, we created our survey. To establish the validity of the survey we distributed the tool to the team and had each group member complete the survey independently and classifying each item into one of our selected entrepreneurial mindset components. Following our validation of the survey items, we had one more round of discussions to resolve any additional concerns with item alignment to the mindset component and phrasing. We made a few minor adjustments to our survey to increase readability and to further clarify the stems of the selected response items. Our final survey contained 29 selected response items and three free response items (see Table 1 for examples of items for each of the four facets we selected for our research). Most of the items were responded to using a Likert scale ranging from "1" representing "Strongly Disagree" to " 5 " which represented "Strongly Agree." However, for some items the responses were made on a Likert-like scale that ranged from " 1 " representing "Never" to "5" representing "Constantly" or on the scale with " 1 " representing "No Comfort" to "5" representing "Extremely Comfortable." It is important to note that we did not define entrepreneur or entrepreneurial mindset in the survey, as we wanted to eliminate the possibility of the definition influencing how the faculty members answered the question. We discussed the possibility that the inclusion of a definition may taint the perceptions of the faculty members, and lead to different responses that may be over-estimations of their engagement in teaching the elements of the entrepreneurial mindset. 
Table 1. Example Items for our Four Facets of the Entrepreneurial Mindset

\begin{tabular}{ll} 
Facet of Teaching the Entrepreneurial & Example Items \\
Mindset & \\
\hline Tolerance for ambiguity & - I do not perceive value in giving students assignments that do not \\
& have a single correct answer. \\
& - How comfortable are you giving your students assignments where \\
& there is no one correct answer? \\
Creativity, Innovative and Novel & - I teach my students how to think creatively. \\
Approaches & - I rarely give my students assignments that require them to seek \\
& information beyond my assigned course readings. \\
Motivation, Resilience, Tenacity, and & - I teach my students how to remain engaged in long-term projects. \\
Acceptance of Failure & - I teach my students that failure is part of learning. \\
Connecting People and Ideas & - I give assignments that require my students to consider multiple \\
& resources to complete. \\
& - I expect my students to know how to effectively connect seemingly \\
& unrelated ideas. \\
Curiosity & The majority of my class projects or assignments require my students \\
& to demonstrate curiosity. \\
& - Each semester I have at least one assignment that requires students to \\
& explore something they are curious about.
\end{tabular}

In addition to our teaching entrepreneurship concepts items, we also developed a small demographic survey. We limited the items in the demographic survey to keep the survey shorter, retain anonymity, and negate the participants' perceiving they could be identified through their responses to the demographic items. We calculated the reliability to be a Cronbach's alpha of .88 indicating a suitable level of reliability.

\subsection{Data Collection}

We uploaded our survey to an online survey site with the first page of the survey displaying the IRB approved letter of interest. An email invitation was sent to the faculty members at a primarily undergraduate university located in the western United States. The email invitation contained a brief statement of the research goals and a link to the survey. We followed our initial invitation with a follow-up reminder about 10 days later. We concluded our data collection after four weeks, as we did not receive any additional responses for a period of five days.

\section{Results}

\subsection{Entrepreneurial Thinking and Definition}

Our first research question asked, "How do faculty members define entrepreneurship and what is their self-perceived levels of entrepreneurial thinking?" To answer this question, we began by examining the participants' responses to our free response item asking them to define entrepreneurship. We found that the majority of the responses (70\%) focused on starting a business, such as, "Starting your own business" and "Pursuing the development of businesses." The remaining $30 \%$ of responses were more generalized to indicate a way of thinking, such as, "Identification of a problem or opportunity and creating an organization to solve or take advantage" and "creative designer of opportunity with a willingness to assume the risk." Thus, the responses reveal a constrained understanding of entrepreneurship by the faculty members.

The next step we took in our analysis was to determine how many entrepreneur mindset elements were present in the descriptions. We found one response in which the definition contained no references to mindset elements, "Independent business person - sole proprietor, small biz owner. Independent of a corporate entity, but interconnected with community." About $44 \%$ of the responses included one facet of the mindset, such as, "Starting a new business" which reflects motivation, and, "A buzzword connoting a modicum of creativity as applied to the business world" which reflects creativity. About $28 \%$ of participant responses included two mindset facets, such as, "Entrepreneurship consists of innovation. Entrepreneurs pursue traditional goals through innovative means" which reflects motivation and innovation, and, "Creativity and niche-targeting in the business world" which reflects 
motivation and creativity. Approximately $23 \%$ of the participants' responses contained references to three mindset facets such as, "creative designer of opportunity with a willingness to assume the risk" which references creativity, opportunity, and risk-taking, and "Identification of a problem or opportunity and creating an organization to solve or take advantage" which references creativity, opportunity, and motivation. Our analysis revealed only two responses (3\%) with four mindset items as part of the response, such as, "The ability to identify a societal need, develop a new or better solution to fulfill that need, and build a business whose purpose is to implement that solution" which reflects creativity, innovation, motivation and opportunity. We found no responses that had five or more entrepreneurial mindset facets.

Of the entrepreneurial mindset facets that we identified, motivation was used in $46 \%$ of the responses, creativity in $21 \%$ of the responses, opportunity in $16 \%$, innovation in $9 \%$, and risk-taking in $8 \%$ of the responses. Thus, it appears that the participants associate entrepreneurship with motivation more than other facets of the mindset.

We continued our analysis with an examination of the responses to our item asking the participants to rate their self-perceived level of entrepreneurial thinking on a scale ranging from " 0 " representing "None" to " 10 " representing "advanced." Our analysis revealed a range from 0 to 10 with an average of $5.39(S=2.72)$. These results suggest that the participants as a whole perceive their level of entrepreneurial thinking as moderate. We then compared the rating of perceived level of entrepreneurial thinking between those whose responses were focused on business and employment with those who provided a more general definition that could be applied more broadly. We found a significant difference $(t=3.05, p=.003)$ between the participants with business and employment focused responses having an average rating of $4.88(S=2.66)$ and those participants with a more general perspective rating at $7.06(S=$ 2.21). Our results suggest that those who report higher levels of entrepreneurial thinking tend to think about entrepreneurship more broadly than those who think of entrepreneurship as being business or employment related.

\subsection{Teaching Facets of Entrepreneurship}

Our second research question asked, "To what level do faculty members engage in teaching facets of the entrepreneurial mindset?" We began answering this question by creating composite scores for the entrepreneurial mindset facets subscales, averaging the outcomes for the related survey items. We progressed next to comparing the composite scores descriptively. The scores range would be from "1" which represents "strongly disagree" or "never" to " 5 " which represents "strongly agree" or "constantly."

Our analysis revealed the faculty members indicated they tend to create contexts for students to develop their innovation and creativity to the highest degree, followed closely by supporting the development of curiosity and working through situations of ambiguity (see Figure 2). While not substantially different, it appears that teaching students to connect people and ideas and to be motivated and tenacious was notably lower. Our results suggest that the faculty members take more responsibility and put forth greater effort to create contexts for students to learn to be innovative and creative, and less effort and responsibility for teaching students to be tenacious and motivated.

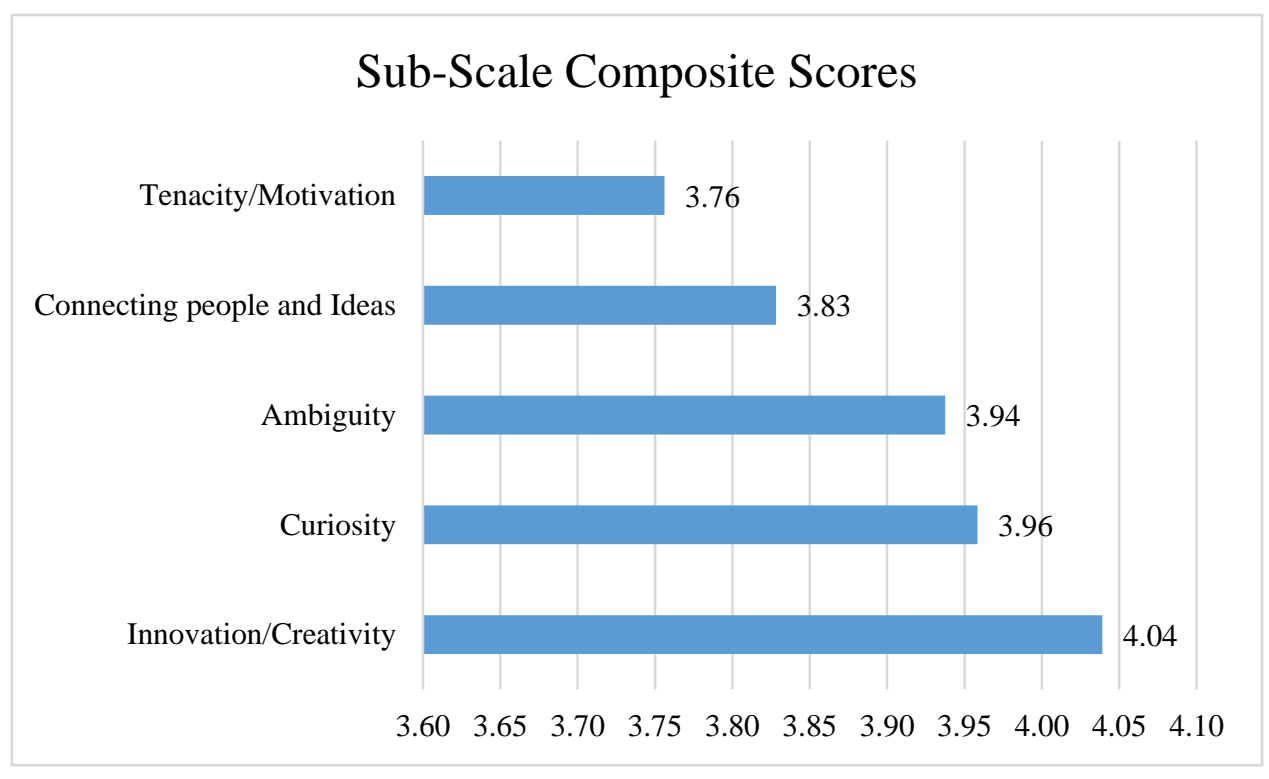

2. The composite scores for our entrepreneurial mindset sub-scales. 
We continued our analysis by comparing the outcomes of the subscales between those whose responses were focused on business and employment with those who provided a more general definition that could be applied more broadly. Our analysis revealed no significant differences suggesting that those who perceive entrepreneurship as starting a business indicate that they attend to facets of the entrepreneurial mindset in the teaching to the same extent as those who conceive entrepreneurship more generally.

We completed this phase of our analysis by examining the correlation between the self-perceived level of entrepreneurial thinking and the subscale scores. We found a significant correlation between the self-perceived level of entrepreneurial thinking and ambiguity $(r=.30, p=.16)$, innovation and creativity $(r=.37, p<.01)$, tenacity and motivation $(r=.39, p<.01)$, and with connecting people and ideas $(r=.39, p<.01)$. We failed to find empirical support for a correlation between self-perceived level of entrepreneurial thinking and teaching curiosity. Our results suggest that increased perceived knowledge of entrepreneurship is likely to lead to greater engagement in instructional approaches that teach entrepreneurial mindset elements, with the exception of curiosity.

\subsection{Entrepreneurship Assignments}

Our third research question asked, "What kinds of assignments do faculty use to foster student entrepreneurial mindset development?" In order to answer this question, we examined the questions that asked faculty members to share how they structure their assignments such that students are required to grapple with ambiguity. We then categorized the responses according to the primary focus of the explanation. We found three dominant approaches faculty members used to engage their students in grappling with ambiguity. The approaches included structuring assignments such that students have to engage in argumentation to justify a position, structuring assignments such that students need to make choices to complete the assignment, and structuring the assignments so that they are open-ended and require students to determine what to do, how to do it, and when the assignment is complete. In a number of responses, participants indicated that they engaged students in ambiguous assignments but did not provide detail. Some of the participants responded that they did not provide their students with ambiguous assignments. The categories and representative responses are provided in Table 2.

Table 2. Ambiguous Assignment Categories and Representative Participant Responses

\begin{tabular}{ll}
\hline Classifying Category & Representative Statement \\
\hline Argumentation & $\begin{array}{l}\text { When I ask students to write, I remind them of the complexity of the world and that the } \\
\text { best arguments acknowledge limitations and strengths, risks and benefits, and } \\
\text { limitations and possibilities } \\
\text { Most assignments have general procedures to follow toward a less defined end. }\end{array}$ \\
Student choice & $\begin{array}{l}\text { Not giving clear direction on how to complete the assignment. The student must } \\
\text { spend time engaging the material and seeking a solution. }\end{array}$ \\
Open-ended & Ambiguity naturally occurs in many of my upper division student driven lab projects. \\
No detail provided - but \\
recognize ambiguity \\
$\begin{array}{l}\text { Don't assign ambiguous } \\
\text { assignments }\end{array}$
\end{tabular}$\quad \begin{aligned} & \text { I don't do this enough. I feel pressure to cover the required material and I am wary of } \\
& \text { adding to my heavy grading load. }\end{aligned}$

Next, we analyzed the responses describing an assignment that required students to use novel thinking. We took a similar approach used in the previous responses to categorizing these responses as well. We found a few assignments that required the students to make connections between different sources of information, many assignments that required students to create something, and many assignments that required the students to evaluate or discover something. The categories and representative responses are provided in Table 3.

Table 3. Novel Thinking Assignment Categories and Representative Participant Responses

\begin{tabular}{ll}
\hline Classifying Category & Representative Statement \\
\hline Making Connections & $\begin{array}{l}\text { Students have to make connections between the cultural artifacts we're studying, } \\
\text { and something from contemporary popular culture. } \\
\text { Using a variety of prewriting methods such as free writing, brainstorming, and } \\
\text { mind mapping to generate ideas for a writing project. } \\
\text { Evaluating }\end{array}$ \\
$\begin{array}{l}\text { I give them an assignment and ask them to look at the world differently in terms of } \\
\text { what other solutions can be arrived at when thinking outside the box. }\end{array}$ \\
\hline
\end{tabular}


Our results indicate that the participants tended to focus on three approaches in designing assignments that require their students to engage in novel thinking. In some of the assignments the participants shared included aspects of other approaches to creating opportunities for novel thinking, but there was clearly a dominant emphasis of one of the approaches in all responses indicating the faculty members tended to use a single approach in their assignments to engage their students in novel thinking.

\section{Discussion}

Given the ever-growing need and opportunities for creativity and innovation in society for finding solutions to pressing problems, there is a high justification for considering the importance of entrepreneurship and the entrepreneurial mindset as being relevant and perhaps critical for all students. The development of the mindset expands their potential success, personal satisfaction, contribution to society, and overall quality of life. Considering entrepreneurial thinking can be taught and learned to better prepare students to adjust to different contexts, opportunities, and conditions of the $21^{\text {st }}$ century, there is support for examining how elements of entrepreneurship are being taught across the disciplines in college campuses.

In our research, we found that most of the faculty members struggled to define entrepreneurship; most indicated it was representative of starting a business. Our results suggest that more work is needed to enhance faculty members' knowledge and understanding of the entrepreneur mindset and how many opportunities in life can be approached using entrepreneurial thinking. Similarly, our finding regarding the self-reported levels of entrepreneurial thinking as associated with the definition of entrepreneurship suggests that those with deeper understanding of entrepreneurship tend to think more in alignment with the entrepreneurial mindset. We believe that deeper understanding of the facets of entrepreneurship could provide faculty members with greater levels of motivation and ability to teach students in ways that enhance their entrepreneurial thinking and perspectives. Future research may focus on the impact of short and long-term interventions and administrative support to prepare faculty members across the disciplines to teach the facets of the entrepreneurial mindset.

In our interpretation of the participants' engagement in teaching facets of the entrepreneurial mindset, faculty indicated that they taught the elements at a level above average (a value of " 3 ") which suggests the faculty members perceive that they teach entrepreneurial thinking, but not in association with being entrepreneurial. The lack of association between level of teaching and focus on the definitions of entrepreneurship (e.g. general entrepreneurial mindset vs. starting a new business) suggests that regardless of how the faculty members defined entrepreneurship, they tended to teach facets of the entrepreneurial mindset as part of their course content in instructional choices. We did, however, find that the self-reported level of entrepreneurial thinking was associated with the levels of engagement in teaching facets of the entrepreneurial mindset. Our finding suggests that as self-awareness of engagement in entrepreneurial thinking increases, there is increased faculty member engagement in teaching their students in ways that support development of the entrepreneurial mindset. Examining how increased knowledge of entrepreneurial thinking by faculty members across the curriculum in making pedagogical and content choices is likely to be a fruitful line of further research.

The faculty members did share a range of methods they used to engage their students in grappling with ambiguity including open-ended assignments, choices students had to make in completing assignments, and requiring students to argue or justify a position with regards to the direction they choose to complete an assignment. While some did not provide lesson specifics, they did indicate some level of value, benefit, or process for engaging students in grappling with ambiguity. We speculate that faculty members likely perceive that engaging their students in assignments that require grappling with ambiguity is likely associated with the faculty members' desire to engage their students in critical thinking. We maintain that grappling with ambiguity does require critical thinking, but also requires other aspects of entrepreneurial thinking such as tenacity, tolerance for the unknown, motivation, and connecting people and ideas. Thus, the context for the assignments in which faculty members engage their students in grappling with ambiguity may be structured to promote their growth along multiple lines of the entrepreneurial mindset, if the assignments explicitly address facets of entrepreneurship. In future research, we may examine ways to enhance faculty members' teaching that include grappling with ambiguity to enhance student development of entrepreneurial thinking. Another direction that may be fruitful for research is an exploration of the relationship between instruction that engages students in grappling with ambiguity and the reaction of the students in relation to their propensity for performance versus a mastery learning orientation.

The participants' sharing of situations in which they engaged their students in conditions that required novel thinking focused on three approaches - making connection, creating, and evaluating. Similar to grappling with ambiguity assignments, the conditions created for the students in which they had to engage in novel thinking were not necessarily linked to the larger development of an entrepreneurial mindset, but were rather isolated from other 
aspects of entrepreneurial thinking such as motivation, tenacity, and tolerance for the unknown. We maintain that providing students with the opportunity to be creative and think in novel ways fosters thinking of new ideas and original solutions, e.g., the assignments could be structured to require other aspects of developing novel solutions such as gather information from a network of people to synthesize a new solution. We argue that faculty members may need targeted professional development opportunities to enhance their understanding of the entrepreneurial mindset to effectively structure course syllabi that require students to consciously engage in entrepreneurial thinking to complete assignments.

\section{Limitations}

The first limitation of our research is that we surveyed faculty members at a single primarily teaching institution. While about $20 \%$ of the faculty of the institution participated in our research, we do not have strong evidence to support and generalize our assertions and conclusions across other similar institutions as the perceptions and experiences of faculty members from those institutions may well be very different. However, given the exploratory nature of our research we wanted to limit our sample size and investigate the greater educational community based on our initial results. Thus, an excellent direction for future research is to expand on our study and gather similar data from a range of institutions and a larger sample of faculty members to determine and expose potential differences or similarities.

The second limitation of our research is the responses provided by the participants may not be reflective of their full understanding or practices of teaching the entrepreneurial mindset. While the definitions of entrepreneurship certainly reflected limited perspectives, it may be possible that faculty member interviews or observations of their teaching may reveal additional insight that our survey was not able to capture. Thus, future research may include the collection of more qualitative data to triangulate the outcomes of the survey and determine if responses to the items are aligned with personal thoughts and teaching.

\section{Conclusion}

Our research addressed a gap in the literature examining how university faculty members across the disciplines teach entrepreneurial thinking. Because people may frame their philosophies and approaches to life using the entrepreneurial mindset and experience greater satisfaction and success, there is a benefit in teaching students entrepreneurial thinking. Having a developed entrepreneurial mindset has many potential benefits such as, increased propensity for positive relationships and personal interaction, being a creative problem solver, remaining motivated in the conditions of adversity, and embracing failure as an opportunity. Our data indicate gaps in faculty knowledge of entrepreneurship and limited focus on enhancing student development of facets of entrepreneurial thinking. The entrepreneurial mindset can be taught and learned. However, the approaches needed to teach the mindset effectively across the disciplines may require targeted faculty professional development. We encourage others to build on our research and continue to explore ways to enhance student development of an entrepreneurial mindset.

\section{References}

Ayala, J. C., \& Manzano, G. (2014). The resilience of the entrepreneur. Influence on the success of the business. A longitudinal analysis. Journal of Economic Psychology, 42, 126-135. https://doi.org/10.1016/j.joep.2014.02.004

Baer, M., Evans, K., Oldham, G. R., \& Boasso, A. (2015). The social network side of individual innovation: A meta-analysis and path-analytic integration. Organizational Psychology Review, 5(3), 191-223. https://doi.org/10.1177/2041386614564105

Beauman, S. S. (2006). Leadership and the clinical nurse specialist: From traditional to contemporary. Newborn and Infant Nursing Reviews, 6(1), 22-24. https://doi.org/10.1053/j.nainr.2005.12.006

Brockhaus, R.H., and P.S. Horwitz (1986), The psychology of the entrepreneur. In D.L. Sexton, and R.W. Smilor, (Eds), The art and science of entrepreneurship (pp. 25-48). Cambridge: Ballinger Publishing Company.

Cai, Y. (2017). From an analytical framework for understanding the innovation process in higher education to an emerging research field of innovations in higher education. The Review of Higher Education, 40(4), 585-616. https://doi.org/10.1353/rhe.2017.0023

Chell, E., Haworth, J., \& Brearley, S. (1991). The entrepreneurial personality: Concepts, cases and categories. London: Routledge.

Chrisman, J. J., Chua, J. H., \& Steier, L. P. (2002). The influence of national culture and family involvement on entrepreneurial perceptions and performance at the state level. Entrepreneurship Theory and Practice, 26(4), 113-130. https://doi.org/10.1177/104225870202600407 
Comadena, M.E. (1984). Brainstorming groups: Ambiguity tolerance, communication apprehension, task attraction, and individual productivity. Small Group Behavior, 15(2), 251-264. https://doi.org/10.1177/104649648401500207

Danes, S. M., Lee, J., Stafford, K., \& Heck, R. K. Z. (2008). The effects of ethnicity, families and culture on entrepreneurial experience: An extension of sustainable family business theory. Journal of Developmental Entrepreneurship, 13(03), 229-268. https://doi.org/10.1142/S1084946708001010

DeRoma, V. M., Martin, K. M., \& Kessler, M. L. (2003). The relationship between tolerance for ambiguity and need for course structure. Journal of Instructional Psychology, 30(2), 104.

Dweck, C. S., Walton, G. M., \& Cohen, G. L. (2014). Academic tenacity: Mindsets and skills that promote long-term learning. Seattle, WA: Bill \& Melinda Gates Foundation.

Essig, L. (2013). Frameworks for educating the artist of the future: Teaching habits of mind for arts entrepreneurship. Artivate: A Journal of Entrepreneurship in the Arts, 1(2), 65-77.

Fisher, R., Maritz, A., \& Lobo, A. (2016). Does individual resilience influence entrepreneurial success? Academy of Entrepreneurship Journal, 22(2), 39.

Fontela, E., Guzmán, J., Pérez, M., \& Santos, F. J. (2006). The art of entrepreneurial foresight. Foresight, 8(6), 3-13. https://doi.org/10.1108/14636680610712496

Foster, J., \& Yaoyuneyong, G. (2016). Teaching innovation: Equipping students to overcome real-world challenges. Higher Education Pedagogies, 1(1), 42-56. https://doi.org/10.1080/23752696.2015.1134195

Furnham, A., \& MacRae, I. (2017). Motivation and performance: A guide to motivating a diverse workforce. London: Kogan Page Limited.

Furnham, A., \& Ribchester, T. (1995). Tolerance of ambiguity: A review of the concept, its measurement and applications. Current Psychology, 14(3), 179-199. https://doi.org/10.1007/BF02686907

Gibb, A.A., (1996), Entrepreneurship and small Business Management: Can we afford to neglect them in the twenty-first century business school? British Journal of Management, 7(4), 309-324. https://doi.org/10.1111/j.1467-8551.1996.tb00121.x

Groves, K., Vance, C., \& Choi, D. (2011). Examining entrepreneurial cognition: An occupational analysis of balanced linear and nonlinear thinking and entrepreneurship success. Journal of Small Business Management, 49(3), 438-466. https://doi.org/10.1111/j.1540-627X.2011.00329.x

Heckhausen, J. (Ed.). (2000). Motivational psychology of human development: Developing motivation and motivating development (Vol. 131). London: Elsevier.

Hindle, K. (2007). Teaching entrepreneurship at university: from the wrong building to the right philosophy. In A. Fayolle (Ed.), Handbook of research in entrepreneurship education, being competitive and successful, (pp 104-126). Chetelham (UK): Edward Elgar Publishing.

Hoerr, T. R. (2013). Fostering grit: How do I prepare my students for the real world? Alexandria, VA: ASCD Arias.

Huber, N. (2003). An experiential leadership approach for teaching tolerance for ambiguity. Journal of Education for Business, 79(1), 52-55. doi:10.1080/08832320309599088

Hvide, H. K., \& Panos, G. A. (2014). Risk tolerance and entrepreneurship. Journal of Financial Economics, 111(1), 200-223. https://doi.org/10.1016/j.jfineco.2013.06.001

Ireland, R. D., Covin, J. G., \& Kuratko, D. F. (2009). Conceptualizing corporate entrepreneurship strategy. Entrepreneurship Theory and Practice, 33(1), 19-46. https://doi.org/10.1111/j.1540-6520.2008.00279.x

Jeraj, M. (2012). Toward the new construct; Entrepreneurial curiosity. In D. Barkovic and B. Runzheimer (Eds.), Interdisciplinary research VIII, (pp 1043-1055). Opatija: Josip Juraj Strossmayer University in Osijek

Johnson, B., Wubbenhorst, W., \& Schroeder, C. (2013). Recidivism reduction and return on investment: An empirical assessment of the Prison Entrepreneurship Program. Waco, TX: Baylor Institute for Studies of Religion Special Report.

Kashdan, T. B., \& Fincham, F. D. (2004). Facilitating curiosity: A social and self-regulatory perspective for scientifically based interventions. In P. A. Linley \& S. Joseph (Eds.), Positive psychology in practice, (pp 482-503). Hoboken, NJ: Wiley. https://doi.org/10.1002/9780470939338.ch30 
Kirby, D. A. (2004). Entrepreneurship education: can business schools meet the challenge? Education+ Training, 46(8/9), 510-519. https://doi.org/10.1108/00400910410569632

Koranda, D., \& Sheehan, K. B. (2014). Teaching curiosity: An essential advertising skill? Journal of Advertising Education, 18(1), 14. https://doi.org/10.1177/109804821401800104

Kuratko, D. F. (2005). The emergence of entrepreneurship education: Development, trends, and challenges. Entrepreneurship Theory and Practice, 29(5), 577-598. https://doi.org/10.1111/j.1540-6520.2005.00099.x

Kuratko, D.F. \& Hodgetts, R.M. (2004).Entrepreneurship: Theory, process, practice. Mason, OH: South-Western College Publishers.

Lee, C. K., \& Benza, R. (2015). Teaching innovation skills: Application of design thinking in a graduate marketing course. Business Education Innovation Journal, 7(1), 43-50.

Lumpkin, G. T., \& Erdogan, B. (2004). If not entrepreneurship, can psychological characteristics predict entrepreneurial orientation? A pilot study. The ICFAI Journal of Entrepreneurship Development, 1(1), 21-33.

Mansfield, R. S., Busse, T. V., \& Krepelka, E. J. (1978). The effectiveness of creativity training. Review of Educational Research, 48(4), 517-536. https://doi.org/10.3102/00346543048004517

Maritz, A. (2010). Networking, entrepreneurship and productivity in universities. Innovation, 12(1), 18-25. https://doi.org/10.5172/impp.12.1.18

Nadelson, L. S., \& Seifert, A. L. (2017). Integrated STEM defined: Contexts, challenges and the future. Journal of Educational Research, 110(3), 221-223. https://doi.org/10.1080/00220671.2017.1289775

Rodov, F. \& Truong, S. (2015). Why schools should teach entrepreneurship. Retrieved from https://www.entrepreneur.com/article/245038

Ryan, R. M., \& Deci, E. L. (2017). Self-determination theory: Basic psychological needs in motivation, development, and wellness. New York: Guilford Publications.

Schunk, D. H., Meece, J. L., \& Pintrich, P. R. (2014). Motivation in education: Theory, research, and application (4th ed.). Boston, MA: Pearson.

Seligman, M. E. (2011). Building resilience. Harvard Business Review, 89(4), 100-6.

Silvia, P. J. (2005). What is interesting? Exploring the appraisal structure of interest. Emotion, 5(1), 89.

Silvia, P. J. (2008). Interest-The curious emotion. Current Directions in Psychological Science, 17(1), 57-60. https://doi.org/10.1111/j.1467-8721.2008.00548.x

Standish - Kuon, T., \& Rice, M. P. (2002). Introducing engineering and science students to entrepreneurship: Models and influential factors at six American universities. Journal of Engineering Education, 91(1), 33-39. https://doi.org/10.1002/j.2168-9830.2002.tb00670.x

Taatila, V. P. (2010). Learning entrepreneurship in higher education. Education+ Training, 52(1), 48-61. https://doi.org/10.1108/00400911011017672

Tegano, D. W. (1990). Relationship of tolerance for ambiguity and playfulness to creativity. Psychological Reports, 66(3), 1047-1056. https://doi.org/10.2466/pr0.1990.66.3.1047

Teoh, H. Y., \& Foo, S. L. (1997). Moderating effects of tolerance for ambiguity and risktaking propensity on the role conflict-perceived performance relationship: Evidence from Singaporean entrepreneurs. Journal of Business Venturing, 12(1), 67-81. https://doi.org/10.1016/S0883-9026(96)00035-3

Vance, C., Zell, D., \& Groves, K. (2008). Considering individual linear/nonlinear thinking style and innovative corporate culture. International Journal of Organizational Analysis, 16(4), 232-248. https://doi.org/10.1108/19348830810944684

Von Culin, K. R., Tsukayama, E., \& Duckworth, A. L. (2014). Unpacking grit: Motivational correlates of perseverance and passion for long-term goals. The Journal of Positive Psychology, 9(4), 306-312. https://doi.org/10.1080/17439760.2014.898320

Wennekers, S., \& Thurik, R. (1999). Linking entrepreneurship and economic growth. Small Business Economics, 13(1), 27-56. https://doi.org/10.1023/A:1008063200484 